\title{
Polymer Enhanced Oil Recovery Process: An Updated, Narrowed Review
}

\author{
Shirazi M1, Kord Sh${ }^{1}$, Jamialahmadi $\mathbf{M}^{1}$ and Tamsilian $\mathrm{Y}^{2 *}$ \\ ${ }^{1}$ Department of Petroleum Engineering, Petroleum University of Technology, Iran \\ ${ }^{2}$ Department of Oil, Gas \& Petrochemical Engineering (OGP), Shahid Chamran University of Ahvaz (SCU), Iran
}

Submission: August 01, 2018; Published: September 24, 2018

*Corresponding author: Tamsilian Y, Faculty of Engineering, Department of Oil, Gas \& Petrochemical Engineering (OGP), Shahid Chamran University of Ahvaz (SCU), Ahvaz, Iran, Tel: +98 6133330010 (5754); Email: tamsilian@scu.ac.ir

\begin{abstract}
Application of polymers and nanoparticles have been suggested by several researchers as a chemical enhanced oil recovery (EOR) agent in carbonate reservoirs each of which has a specific influence on the reservoir rock and fluid properties. However, the high salinity of the reservoir condition along with high temperature has a detrimental effect on the performance of both polymers and nanoparticles. Common polymers and nanoparticles are usually degraded and begin to aggregate with the salinity increment. The purpose of this research is to provide a comprehensive review on the combination of general/thermoassociative polymers with low salinity water and nanoparticles as three new approaches for the chemical EOR process. The most previous studies have been concerned application of polymers and nanoparticles in the EOR, recommending usage of thermoassociative polymers (resistant under high salinity and high temperature conditions) as a substitution of common viscosifiers, and also as a good stabilizer of nanofluids to provide a higher stability for nanoparticles. All makes new polymer materials as a promising candidate for offering some ideas to see the polymer complexity world and its pros/cons as a one of the promising EOR agent.
\end{abstract}

Keywords: General polymer; Tanoparticle; Thermoassociative polymers; EOR process

Abbreviations: EOR: Enhanced Oil Recovery; IFT: Interfacial Tension; PAM: Polyacrylamide; HPAM: Hydrolyzed PAM; HSHT: High Salinity and High Temperature; LoSal: Low Salinity; CTAB: Cetrimonium Bromide; SDS: Sodium Dodecyl Sulfate; CMC: Critical Micelle Concentration; PVP

Polyvinylpyrrolidone; PPNs: Polyacrylamide Nanoparticles; PSt: Polystyrene; TAP: Thermo Associative Copolymers

\section{Introduction}

Carbonate reservoirs account for more than $60 \%$ of the world's oil. However, due to the presence of the fracture network and oil-wet matrix, oil recovery from naturally fractured carbonate reservoirs has always been a challenging issue. Hence, application of EOR methods especially chemical EOR has been recently gained a lot of attention by researchers to obtain a higher recovery of carbonate reservoirs. Application of polymers and nanoparticles are a good example of chemical agents each of which has a specific effect on the reservoir rock and fluid properties. The govern mechanism of polymer flooding is the viscosity enhancement of aqueous solution, while nanoparticles lead to the Interfacial Tension (IFT) reduction and wettability alteration of reservoir rocks. Common polymers such as Polyacrylamide (PAM) and Hydrolyzed PAM (HPAM) usually exhibit a high degree of chemical degradation against High Salinity and High Temperature (HSHT) reservoirs which results in the solution viscosity reduction with the salinity and temperature increment [1]. Hence, various researches have been conducted concerning application of Low Salinity (LoSal) water with polymers in order to mitigate the detrimental effect of high salinity [2-4]. High salinity also has a worse effect on nanofluids stability [5]. However, application of thermoassociative polymers which are stable in high salinity and high temperature conditions, can be a good agent compensate for the effect of high salinity on polymers and it can also be applied as a stabilizer for nanofluid solutions to obtain a higher stable nano-suspension.

In this paper, a comprehensive review of the most recent studies has been conducted in order to analyze the application of the polymers combination with low salinity water, nanoparticles, and combination of nanoparticles (NPs) and thermoassociative polymers in EOR process.

\section{Results and Discussion}

\section{Combination of Polymers with Low Salinity Water}

Shiran et al., [2], investigated the effect of the low salinity water and hydrolyzed HPAM on the oil recovery and observed an increment in the total recovery which is mainly due to the combination effect. Vermolen et al., [1], expressed these combination effects and claimed that combination of the LoSal/polymer will improve the oil sweep efficiency through the trapped oil mobilization which are detached from the rock 
surface due to the wettability alteration. In order to precisely shown the effect of brine salinity on polymer solution viscosity, a semi-log diagram of polymer viscosity vs. brine salinity is shown in Figure 1. As it is obvious, two plateau ranges are observed where the reservoir brine salinity is in the ranges of lower plateau, while low salinity brine is on the steep part of the graph in which the polymer viscosity is highly sensitive to the brine salinity. They concluded that the amount of the required polymer for obtaining a target viscosity is lowered by the usage of LoSal which is favorable for economic considerations. Furthermore, they observed an increase in the stability of polymer at the high temperatures when it is combined with LoSal confirming the application of LoSal/polymer at high salinity and high temperature conditions.

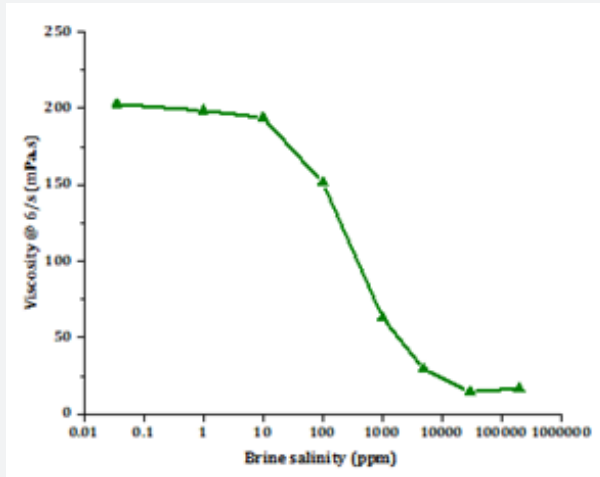

Figure 1: Viscosity vs. salinity curve for a normal HPAM at a shear rate of $6 s-1$ [1].

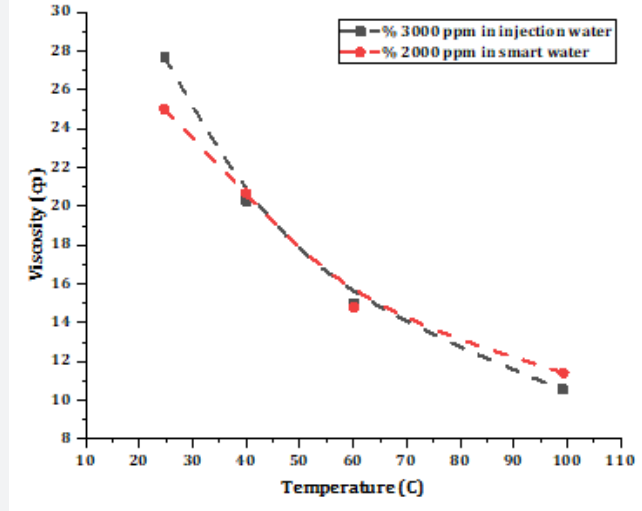

Figure 2: Polymer solution viscosities at different temperatures and concentrations in conventional injection water and smart water [3]

Recently, AlSofi et al., [3] have investigated the simultaneous usage of a sulfonated polyacrylamide polymer with the smart water (salinity of 10 times lower than the injected water) and they observed the required polymer concentration for achieving a specific viscosity is reduced (from 3,000 ppm to 2,000 ppm) in the case of smart water instead of high salinity ones (Figure 2). Besides, core-flooding experiments have shown a significant increment in the oil recovery by smart water/polymers comparing to the separate cases. The effect of LoSal combination with the polymer on controlling polymer gel blocking in the fractured reservoirs have been analyzed by Brattekas et al. [4]. They observed that the gel fracture blocking is improved via LoSal as a chase water. Hence, the fractures will be successfully blocked to divert the flow direction toward matrix blocks.

\section{Standalone Nanoparticles for EOR Purposes}

Due to the unique properties of nanoparticles, their applications have been recently suggested as a promising EOR method. NPs have small size ( 1 to $100 \mathrm{~nm}$ ) assisting them to flow through a typical reservoir pore spaces (lower than 1 micron). Besides, their surface properties can be manipulated in order to become more appropriate for desirable application [6]. In order to get insight into the actual mechanisms by which NPs improve the oil recovery from reservoirs, a number of researches have been conducted that some of them are explained below.

$\mathrm{SiO}_{2}$ : The applicability of hydrophilic $\mathrm{SiO}_{2}$ NPs on the efficiency of Cetrimonium Bromide (CTAB) as a cationic surfactant has been analyzed by Ravera et al. [7]. A reduction in the IFT was observed due to the adsorption of positively charged CTAB on the surface of silica NPs (in 1wt\% nanosuspension). In another research conducted by Ma et al. in 2008, the efficiency of Hydrophilic $\mathrm{SiO}_{2}$ NPs was also analyzed on the performance of Sodium Dodecyl Sulfate (SDS) as an anionic surfactant and Triton X-100 as a non-ionic surfactant. They observed hydrophilic $\mathrm{SiO}_{2}$ NPs improve the influence of SDS in the IFT reduction which may be due to the presence of repulsive forces between negatively charged SDS and $\mathrm{SiO}_{2} \mathrm{NPs}$. However, they do not affect the performance of Triton X-100 because of existing poor interactions [8]. Zargartalebi et al., [9] investigated the influence of hydrophilic and slightly hydrophobic $\mathrm{SiO}_{2} \mathrm{NPs}$ $(0.2 \mathrm{wt} \%)$ on the SDS performance, observed a reduction in the surfactant adsorption on the sandstone surface in the presence of NPs especially for hydrophobic ones. Besides, they claimed that the influence of NPs on the IFT reduction was completely dependent on the surfactant concentration. As it is illustrated in Figure 3a and Figure 3b, at low surfactant concentration up to Critical Micelle Concentration (CMC), IFT values continuously reduced. However, above CMC value, the IFT began to increase and finally reached to a constant value even lower than the one obtained by surfactant alone.

The ability of silane treated $\mathrm{SiO}_{2}$ and hydrophobic $\mathrm{SiO}_{2} \mathrm{NPs}$ (with a concentration of $0.3 \mathrm{wt} \%$ dispersed in ethanol) in the wettability alteration of reservoir rock has been firstly observed by Ogolo et al. in 2012 [10]. After a year, Li et al. confirmed the high efficiency of hydrophilic $\mathrm{SiO}_{2}$ NPs in both IFT reduction and wettability alteration of sandstones in the presence of $30,000 \mathrm{ppm} \mathrm{NaCl}$ solution with $0.05 \mathrm{wt} \% \mathrm{NPs}$, showing an optimum concentration [11]. Furthermore, Roustaei et al., [12] investigated the potential of hydrophilic $\mathrm{SiO}_{2} \mathrm{NPs}$ in the presence of $50,000 \mathrm{ppm} \mathrm{NaCl}$ solution in EOR of carbonate rocks and they concluded that at an optimum concentration of $0.4 \mathrm{wt} \%$, maximum wettability alteration is obtained. They also claimed that NPs result in increasing IFT when the wettability is altered 
toward water-wetness and this IFT increment contributes in the oil recovery improvement. Their assertion is based on the concept of spontaneous imbibition in carbonate reservoirs. Recently, the effect of temperature and size of $\mathrm{SiO}_{2} \mathrm{NPs}$ has been analyzed by Al-Anssari et al., [13] and they concluded that the temperature has a positive effect on $\mathrm{SiO}_{2} \mathrm{NPs}$ ability to alter wettability of oil-wet carbonate rocks; however, the effect of NPs size is negligible.

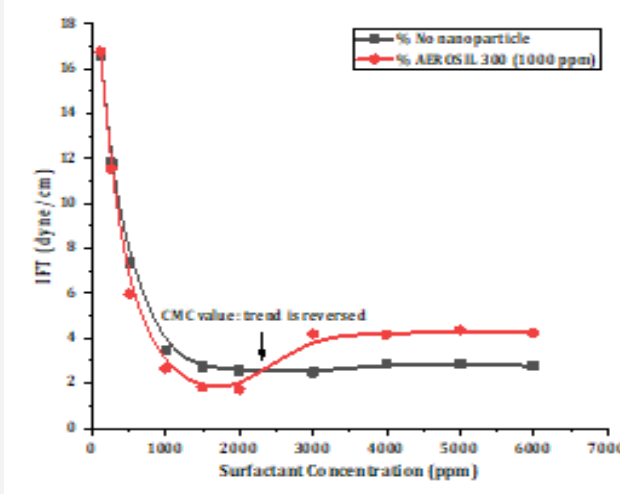

[a]

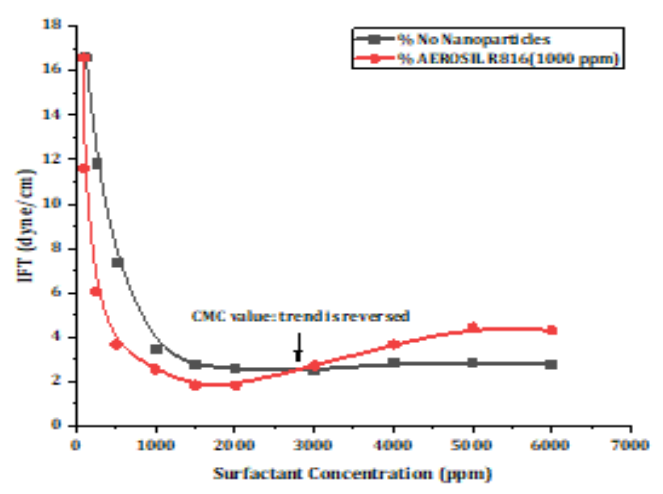

[b]

Figure 3: Oil/water IFT for aqueous nanoparticle-augmented surfactant solutions of different surfactant concentrations at constant NPs concentrations. a) hydrophilic AEROSIL 300 NPs and b) hydrophobic AEROSIL R816 NPs [9].

$\mathrm{ZrO}_{2}$ : Karimi et al., [14] investigated the process of spontaneous imbibition of $5 \mathrm{wt} \% \mathrm{ZrO}_{2}$ nanofluid into an oil-wet carbonate reservoir. They claimed that adsorption of hydrophilic synthesized $\mathrm{ZrO}_{2}$ NPs and the mixture of nonionic surfactants onto the rock surface leads to the formation of a nano-textured surface which can modify reservoir rock wettability toward more water-wetness better than NPs alone and consequently more oil is recovered.

$\mathrm{Al}_{2} \mathrm{O}_{3}$ : Ogolo et al., [10] claimed that $\mathrm{Al}_{2} \mathrm{O}_{3} \mathrm{NPs}$ (dispersing in distilled water or brine with a salinity of $30,000 \mathrm{ppm}$ ) perform well in EOR due to the oil viscosity reduction. However, a year later, Giraldo et al., [15] observed that $\mathrm{Al}_{2} \mathrm{O}_{3}$ can also alter the wettability of sandstones from severe oil-wet to severe waterwet when synthesized by an anionic surfactant. Among a wide range of nanofluid concentration between 0.01 to $1 \mathrm{wt} \%$, the efficiency of surfactant to wettability modification is improved just at a relatively low NPs concentration (equal or lower than $0.05 w t \%)$. Besides, they asserted that imbibition experiments are a good evaluation tool for analyzing the performance of NPs. The ability of $\mathrm{Al}_{2} \mathrm{O}_{3} \mathrm{NPs}$ for IFT reduction is expressed by Joonaki et al., [16] and they observed that the interfacial tension between phases began to reduce when propanol is used as a dispersing agent for $\mathrm{Al}_{2} \mathrm{O}_{3} \mathrm{NPs}$.

$\mathrm{TiO}_{2}$ : Ehtesabi et al., [17] investigated the application of synthesized $\mathrm{TiO}_{2}$ NPs through core-flooding experiments in sandstone rocks and they confirmed their application in EOR in terms of wettability alteration and oil viscosity reduction. They observe that $\mathrm{TiO}_{2}$ NPs do not affect the oil viscosity but in a low concentration of $0.01 \mathrm{wt} \%$ could alter significantly the wettability of rock surface. Application of $\mathrm{SiO}_{2}, \mathrm{Al}_{2} \mathrm{O}_{3}$ and $\mathrm{TiO}_{2}$ NPs in oil-wet carbonate reservoirs have been analyzed by Esfandyari et al., [5] under various temperatures (26, 40,
$50,60{ }^{\circ} \mathrm{C}$ ). The maximum and minimum reduction in contact angles were achieved by $\mathrm{SiO}_{2}$ and $\mathrm{Al}_{2} \mathrm{O}_{3} \mathrm{NPs}$, respectively at all temperatures. Besides, they observed a reduction in oil viscosity at higher temperatures of 50 and $60{ }^{\circ} \mathrm{C}$ by $\mathrm{Al}_{2} \mathrm{O}_{3}$ and $\mathrm{TiO}_{2} \mathrm{NPs}$ and the oil recovery by $\mathrm{Al}_{2} \mathrm{O}_{3}$. $\mathrm{TiO}_{2}$ was also more significant at all temperatures comparing to $\mathrm{SiO}_{2} \mathrm{NPs}$. The potential of these three hydrophilic NPs has been also investigated by Hendraningrat et al. in different wettability sandstone reservoirs. They confirmed the mechanism of wettability alteration as the main mechanism of these NPs although IFT reduction is also observed. As a result of their experiments, $\mathrm{TiO}_{2}$ NPs performed well in all types of wettability systems among other NPs [18]. Generally, the mechanism by which NPs alter the reservoir rock wettability is due to the creation of a wedge-film on the rock surface due to the disjoining pressure enhancement between oil and rock surface (Figure 4). Consequently, the oil droplets will detach from the rock surface and a new underlying layer is exposed with a more water-wetness wettability [19].

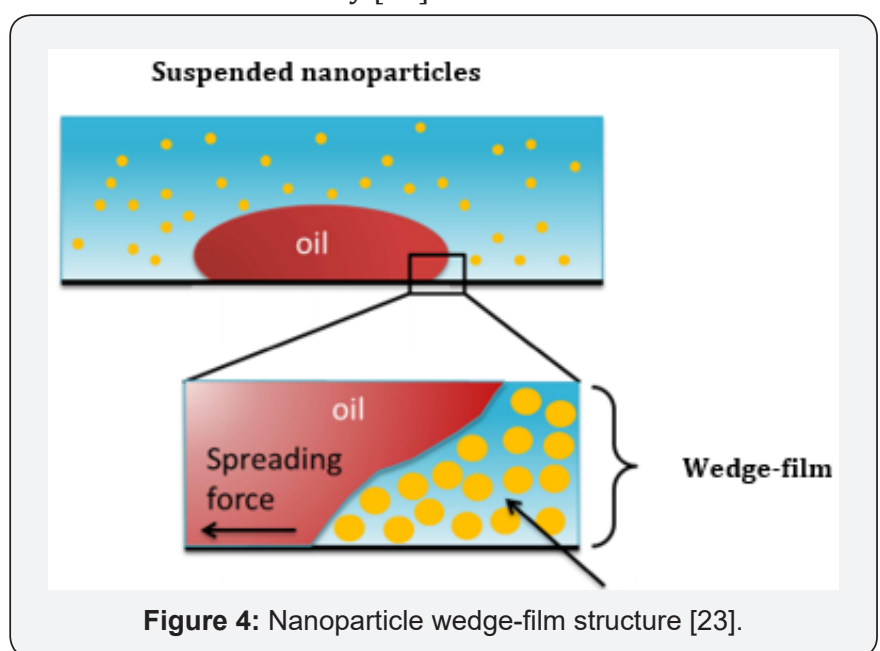




\section{Stability of Nanoparticles}

One of the main challenges of nanofluids which limits their application especially in long period is their stability. Forming an agglomeration may restrict the flow of NPs through micronsized pore spaces and may lead to pore spaces plugging and permeability reduction [18]. Zeta potential of nanofluid has a direct relationship with the suspension stability in a way that the suspension with higher zeta potential (even positive or negative) shows higher stability. The water chemistry such as $\mathrm{pH}$, ionic strength (salinity) and its various component usually influence the stability of nanofluids [20]. Accordingly, it is expected that adjusting the $\mathrm{pH}$ value of system, reducing its salinity or adding a stabilizer to the nano-suspension will provide a higher stability for system. Adjusting $\mathrm{pH}$ value: The $\mathrm{pH}$ value of a nanofluid solution influence their surface charge and consequently their stability. According to Huang et al. there exist an optimal $\mathrm{pH}$ value by which a maximum nanofluid stability is obtained. They have conducted a series of experiments on $\mathrm{Al}_{2} \mathrm{O}_{3}$ and $\mathrm{CuO}$ nanofluids in which the $\mathrm{pH}$ value of the solution is adjusted by addition of $\mathrm{HCl}$ or $\mathrm{NaOH}$ to obtain an acidic or basic suspension. They observed that $\mathrm{Al}_{2} \mathrm{O}_{3}$ and $\mathrm{CuO}$ nano-suspension obtain the highest stability at an optimum $\mathrm{pH}$ value of 7.5- 8.9 and 7.5-9.5, respectively [21].

Effect of salinity: Esfandyari et al., [5] measured the zeta potential of the nanofluid of $\mathrm{Al}_{2} \mathrm{O}_{3}, \mathrm{TiO}_{2}$ and $\mathrm{SiO}_{2}$ in various dispersion media of deionized water, $\mathrm{NaCl}$ solution $(3,000$ ppm) and synthetic brine $(25,000 \mathrm{ppm})$. As a result of their experiments, the zeta potential values of $\mathrm{SiO}_{2}, \mathrm{Al}_{2} \mathrm{O}_{3}$ and $\mathrm{TiO}_{2}$ in deionized water are $-38.5,31.1$ and $-19.1 \mathrm{mV}$, respectively indicating the highest to lowest stable nanofluids. However, the zeta potential values of $\mathrm{SiO}_{2}, \mathrm{Al}_{2} \mathrm{O}_{3}$ and $\mathrm{TiO}_{2}$ nanofluids have been decreased to $-32.3,27.4$ and -15.8 in $\mathrm{NaCl}$ solution and to $-22.4,21.6$ and -9.9 in the synthetic brine respectively, all of which indicate the detrimental effect of salinity on the stability of nanofluids.

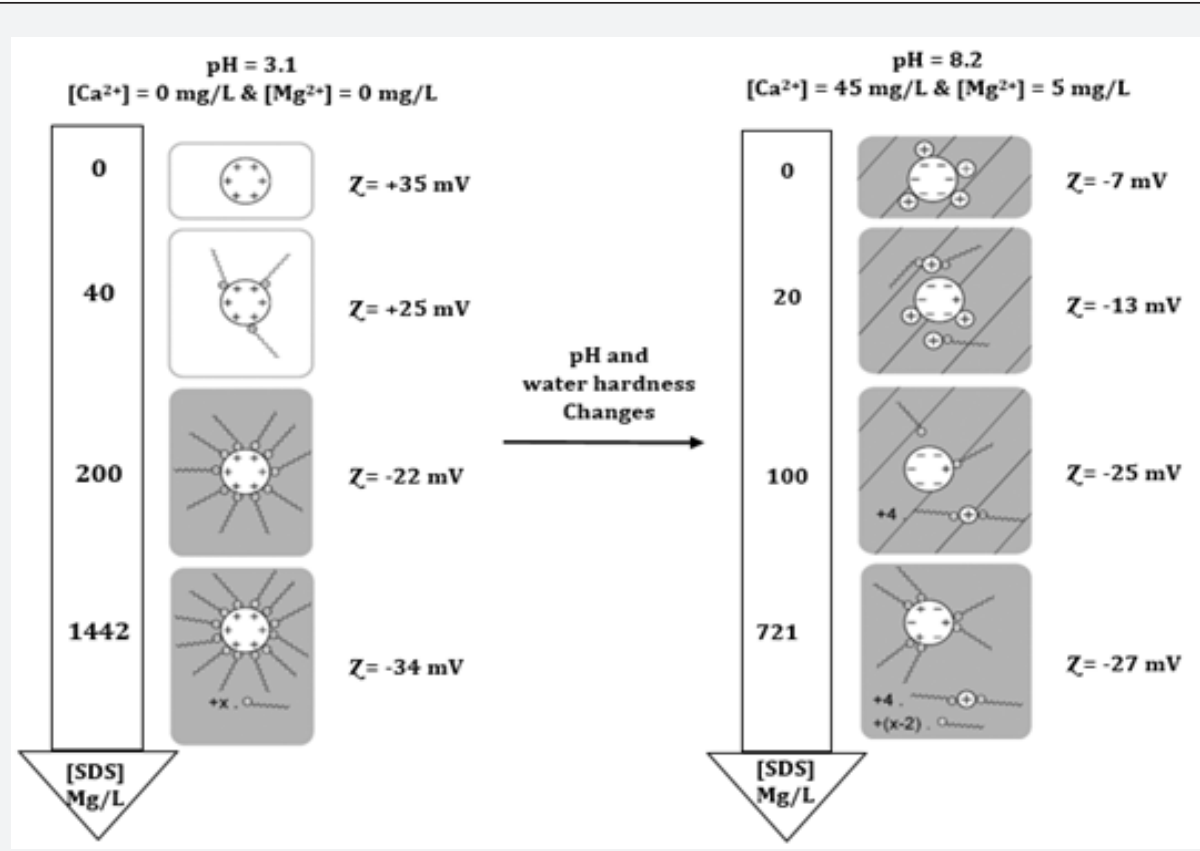

Figure 5: Schematic illustration of $\mathrm{TiO}_{2}$-SDS complex behavior after an important $\mathrm{pH}$ change and in the presence of divalent cations. Hashed squares represent destabilized $\mathrm{TiO}_{2}$-SDS complexes. Empty or grey squares represent respectively positively and negatively charged surfaces at [TiO2] $=0.005 \mathrm{wt} \%$ [20].

Adding stabilizer: Hendraningrat et al., [18] analyzed the stability of nanofluid of $\mathrm{Al}_{2} \mathrm{O}_{3}, \mathrm{TiO}_{2}$ and $\mathrm{SiO}_{2} \mathrm{NPs}$. Analysis of nanofluids visual stability show that $\mathrm{Al}_{2} \mathrm{O}_{3}$ NPs precipitated at initial stages (approximately after $3 \mathrm{hs}$ ) and $\mathrm{TiO}_{2} \mathrm{NPs}$ precipitated slightly later. However, $\mathrm{SiO}_{2}$ NPs exhibit a better stability of 24-48hrs. In order to get longer stability of $\mathrm{Al}_{2} \mathrm{O}_{3}$ and $\mathrm{TiO}_{2}$ NPs, they proposed addition of Polyvinylpyrrolidone (PVP) as a stabilizer to alter NPs surface conductivities, resulting in 96 and $48 \mathrm{~h}$ stability for $\mathrm{Al}_{2} \mathrm{O}_{3}$ and $\mathrm{TiO}_{2}$ nanofluids, respectively. The influence of $\mathrm{pH}$ value, existence of divalent cations presented in water and surfactant concentration as a stabilizer on $\mathrm{TiO}_{2}$ nanofluid stability have been analyzed by Loosli et al. [20]. They observed that when the $\mathrm{pH}$ values are altered from $\mathrm{pH}=3$ (addition of $\mathrm{HCl}$ ) to $\mathrm{pH}=11$ (addition of $\mathrm{NaOH}$ ) the zeta potential continuously decreased from $+36 \mathrm{mV}$ to $-40 \mathrm{mV}$. At a $\mathrm{pH}$ range of 5-7.2, the absolute zeta potential values are minimum indicating the range of instability. Zeta potential is equal to zero at a $\mathrm{pH}$ value of 6.1 , indicating the most instable situation. Besides, they also concluded that the presence of divalent cations $\left(\mathrm{Ca}^{2+}\right.$ and $\mathrm{Mg}^{2+}$ ) leads to the more agglomeration of NPs due to the cation bridging. In contrast, they claimed that adsorption of negatively charged sodium dodecyl sulfate, as an anionic surfactant, onto the positively charged surface of $\mathrm{TiO}_{2} \mathrm{NPs}$ make the nano-suspension more stable. The influence of $\mathrm{pH}$ changes and the presence of divalent cations on the stability of $\mathrm{TiO}_{2}$-SDS complexes are illustrated in Figure 5. 


\section{Thermoassociative polymers}

In order to prevent chemical degradation of commercial PAM during EOR in high salinity and high temperature conditions, Tamsilian et al., [22] have synthesized a protected Polyacrylamide Nanoparticles (PPNs) in which a hydrophobic polystyrene (PSt) sell is created by one-pot two-step inverse emulsion surface polymerization method. The existence of hydrophobic PSt shell protects the active PAM chains from degradation in harsh reservoir conditions. Besides, the efficiency of PPNs as a viscosity modifier is increased by their timedependent releasement; hence, it will remain active in a wide range of approximately 30 days. A schematic of PPNs polymer flooding is illustrated in Figure 6. PPNs have a high potential of IFT reduction and wettability alteration in comparison with common PAM and according to the results of incremental oil recovery, an average of $6.9 \%$ and $5.95 \%$ was obtained by PPNs and PMA, respectively; which indicates PPNs better capability in oil recovery improvement. Finally, a comparison between the performance of PAM and PPN introduces PPNs as a good candidate for EOR processes, due to their high capability in viscosity increment even harsh conditions and also IFT reduction and wettability alteration although a lower amount of it is required for achieving same recovery.

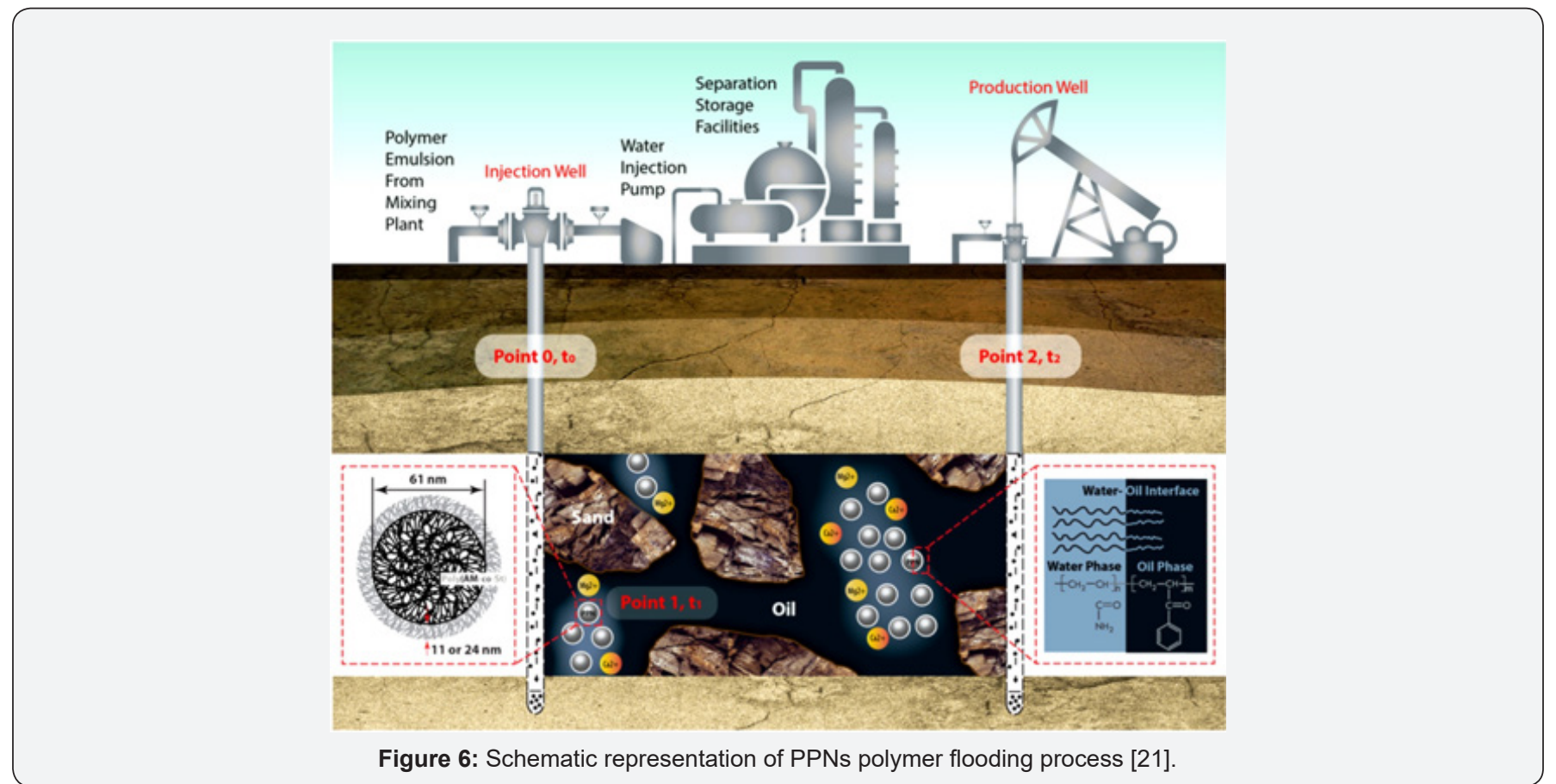

Shaban et al., [23] have synthesized a new cauliflower- are required. They concluded that their new method of synthesis like amphiphilic copolymer by aerosol-photopolymerization has a great ability to produce novel copolymers with large method. A schematic of their experimental setup consists of an amount of hydrophobic and hydrophilic monomers. Hence, it has atomizer, a flow-through photoreactor, and a collection filter a long applicability to viscosity enhancement during the process is shown in Figure 7. The advantage of this method over usual of polymer-flooding. methods such as emulsion polymerization is that no surfactants

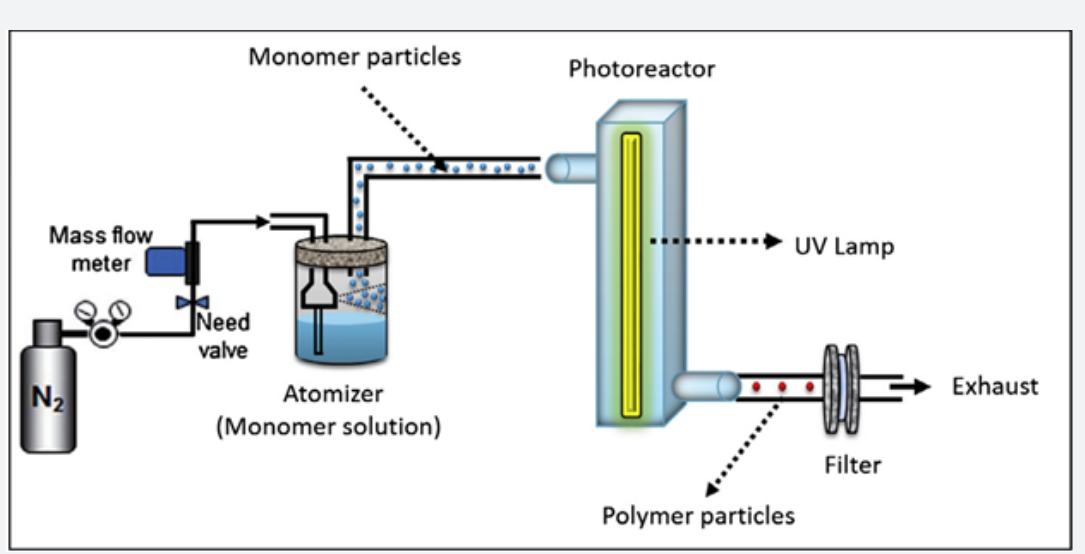

Figure 7: Schematic of the continuous experimental setup of aerosol based photopolymerization method [22]. 
Another new type of acrylamide-based Thermo Associative Copolymers (TAP), applicable in high salinity and high temperature reservoirs, have been considered by the current research community, called Nano Chemical Group, through the process of a copolymerization mechanism of free-radical of acrylamide monomer and thermosensitive macromonomers. In a saline reservoir, the viscosity of a solution is augmented if the temperature is above a critical value called associating temperature. Meanwhile, it is expected that addition of a type of stabilizer which is highly resistant in high salinity conditions could provide a desired stability for nanofluids at high salinity conditions. Considering this in mind, the novel hydrophobically thermoassociating copolymer (HTAP) consisting of polyacrylamide and polystyrene, prepared by Tamsilian et al., [22], which has been recently used as EOR agent is recommended to stabilize NPs to compensate for the detrimental effect of high salinity.

\section{Conclusion}

In this study, a comprehensive review has been conducted on the combination of polymers with low salinity water, nanoparticles, and thermo associative polymers, providing three new approaches for the polymer EOR process. The following conclusions can be obtained from the reviewed researches:

I. Due to the negative impact of the salinity on the efficiency of polymer, application of low salinity water with common polymers mitigates its worse effect, resulting in more oil recovery. Besides, the required polymer amount for achieving the same viscosity is lower comparing to the cases in which high salinity water is used.

II. $\mathrm{SiO}_{2}$ nanoparticles results in more oil recovery by the wettability alteration of the reservoir rock and IFT reduction. $\mathrm{ZrO}_{2}$ and $\mathrm{TiO}_{2}$ nanoparticles by wettability alteration and $\mathrm{Al}_{2} \mathrm{O}_{3}$ nanoparticles by IFT reduction, wettability alteration and oil viscosity reduction lead to oil recovery improvement all of which are among the effective nanoparticles.

III. The stability of nanofluids is affected by the water chemistry such as $\mathrm{pH}$, ionic strength (salinity) and its various components. There exists an optimum value of $\mathrm{pH}$ by which maximum stability is obtained for each nanofluid. Salinity has usually a detrimental effect on nanofluids stability and result in their agglomeration.

IV. Thermoassociative polymers which their efficiency remain stable at the high salinity and high temperature conditions, are suggested as a promising substitution for common polymers and also as a stabilizer of nanofluids at high salinity harsh conditions.

V. Reviewing these three aspects of polymer applications in the EOR process shows a good thought streamline for research groups who are active to see the polymer complexity world and its pros/cons as a one of the promising EOR agent.

\section{References}

1. Vermolen EC, Pingo-Almada M, Wassing BM, Ligthelm DJ, Masalmeh SK (2014) Low-salinity Polymer Flooding: Improving Polymer Flooding Technical Feasibility and Economics by Using Low-salinity Make-up Brine. International Petroleum Technology Conference, Qatar, pp. 15.

2. Shaker Shiran B, Skauge A (2013) Enhanced Oil Recovery (EOR) by Combined Low-salinity Water/Polymer Flooding. Energy \& Fuels 27(3): 1223-1235.

3. AlSofi AM, Wang J, AlBoqmi AM, AlOtaibi MB, Ayirala SC, et al. (2016) Smart Water Synergy with Chemical EOR for a Slightly Viscous Arabian Heavy Reservoir. SPE Heavy Oil Conference and Exhibition, Society of Petroleum Engineers, Kuwait, pp. 11.

4. Brattekås B, Graue A, Seright RS (2015) Low-salinity Chase Water Floods Improve Performance of $\mathrm{Cr}$ (III)-acetate HPAM Gel in Fractured Cores. SPE International Symposium on Oilfield Chemistry, Society of Petroleum Engineers, USA, pp.17.

5. Esfandyari Bayat A, Junin R, Samsuri A, Piroozian A, Hokmabadi M (2014) Impact of Metal Oxide Nanoparticles on Enhanced Oil Recovery from Limestone Media at Several Temperatures. Energy \& Fuels 28(10): 6255-6266.

6. Kapusta S, Balzano L, Te Riele PM (2011) Nanotechnology Applications in Oil and Gas Exploration and Production. International Petroleum Technology Conference, International Petroleum Technology Conference, Thailand: pp. 5.

7. Ravera F, Santini E, Loglio G, Ferrari M, Liggieri L (2006) Effect of Nanoparticles on the Interfacial Properties of Liquid/Liquid and Liquid/Air Surface Layers. The Journal of Physical Chemistry B 110(39): 19543-19551.

8. Ma H, Luo M, Dai LL (2008) Influences of Surfactant and Nanoparticle Assembly on Effective Interfacial Tensions. Physical Chemistry Chemical Physics 10(16): 2207-2213.

9. Zargartalebi M, Barati N, Kharrat R (2014) Influences of Hydrophilic and Hydrophobic Silica Nanoparticles on Anionic Surfactant Properties: Interfacial and Adsorption Behaviors. Journal of Petroleum Science and Engineering 119: 36-43.

10. Ogolo NA, Olafuyi OA, Onyekonwu MO (2012) Enhanced Oil Recovery Using Nanoparticles. SPE Saudi Arabia section technical symposium and exhibition, Society of Petroleum Engineers, Saudi Arabia, pp. 9.

11. Li S, Hendraningrat L, Torsaeter O (2013) Improved Oil Recovery by Hydrophilic Silica Nanoparticles Suspension: 2 Phase Flow Experimental Studies. International Petroleum Technology Conference, China, pp. 15.

12. Roustaei A, Bagherzadeh H (2015) Experimental Investigation of $\mathrm{SiO}_{2}$ Nanoparticles on Enhanced Oil Recovery of Carbonate Reservoirs. Journal of Petroleum Exploration and Production Technology 5(1): 27-33.

13. Al-Anssari S, Wang S, Barifcani A, Lebedev M, Iglauer S (2017) Effect of Temperature and $\mathrm{SiO}_{2}$ Nanoparticle Size on Wettability Alteration of Oil-wet Calcite. Fuel 206: 34-42.

14. Karimi A, Fakhroueian Z, Bahramian A, Pour Khiabani N, Darabad JB, et al. (2012) Wettability Alteration in Carbonates Using Zirconium Oxide Nanofluids: EOR Implications. Energy \& Fuels 26(2): 1028-1036.

15. Giraldo J, Benjumea P, Lopera S, Cortés FB, Ruiz MA (2013) Wettability Alteration of Sandstone Cores by Alumina-based Nanofluids. Energy \& Fuels 27(7): 3659-3665.

16. Joonaki E, Ghanaatian S (2014) The Application of Nanofluids for Enhanced Oil Recovery: Effects on Interfacial Tension and Core Flooding Process. Petroleum Science and Technology 32(21): 25992607. 
17. Ehtesabi H, Ahadian MM, Taghikhani V, Ghazanfari MH (2013) Enhanced Heavy Oil Recovery in Sandstone Cores Using $\mathrm{TiO}_{2}$ Nanofluids. Energy \& Fuels 28(1): 423-430.

18. Hendraningrat L, Torsæter O (2015) Metal Oxide-based Nanoparticles: Revealing their Potential to Enhance Oil Recovery in Different Wettability Systems. Applied Nanoscience 5(2): 181-199.

19. Lau HC, Yu M, Nguyen QP (2017) Nanotechnology for Oilfield Applications: Challenges and Impact. Journal of Petroleum Science and Engineering 157: 1160-1169.

20. Loosli F, Stoll S (2017) Effect of Surfactants, pH and Water Hardness on the Surface Properties and Agglomeration Behavior of Engineered $\mathrm{TiO}_{2}$ Nanoparticles. Environmental Science: Nano 4(1): 203-211.
21. Huang J, Wang X, Long Q, Wen X, Zhou Y, et al. (2009) Influence of $\mathrm{pH}$ on the stability characteristics of nanofluids. In Photonics and Optoelectronics, IEEE, China.

22. Tamsilian Y, Ahmad Ramazani SA, Shaban M, Ayatollahi S, de la Cal JC, et al. (2016) Nanostructured Particles for Controlled Polymer Release in Enhanced Oil Recovery. Energy Technology 4(9): 1035-1046.

23. Shaban M, SA AR, Ahadian MM, Tamsilian Y, Weber AP (2016) Facile Synthesis of Cauliflower-like Hydrophobically Modified Polyacrylamide Nanospheres by Aerosol-photopolymerization. European Polymer Journal 83: 323-336.

\section{Your next submission with Juniper Publishers will reach you the below assets}

- Quality Editorial service

- Swift Peer Review

- Reprints availability

- E-prints Service

- Manuscript Podcast for convenient understanding

- Global attainment for your research

- Manuscript accessibility in different formats ( Pdf, E-pub, Full Text, Audio)

- Unceasing customer service

Track the below URL for one-step submission https://juniperpublishers.com/online-submission.php 